\title{
Norval Baitello Junior \\ O inóspito: uma pequena arqueologia do conceito de espaço no pensamento de Vilém Flusser ${ }^{1}$
}

\section{O inóspito: o estrangeiro e o inimigo em nosso espaço}

Essa palavra merece, precisa de explicação. Então começo por aí. Como Flusser tanto gostava, devese resgatar a etimologia, a história das palavras, sua arqueologia. Vivemos na era em que as ciências arqueológicas começam a tomar o espaço das ciências normativas. A palavra inóspito vem do latim hospitalitas e que significa "condição do estrangeiro". Ou, então, do mesmo núcleo de significado, fazem parte outras palavras em latim, como hospitium, que significava "aposento" ou "hospitalidade". Ou, então, hospes, hospitis, que significava "hóspede" ou "estrangeiro" ou "viajante". E ainda hostis, "estrangeiro", "forasteiro", "inimigo". Então a palavra portuguesa inóspito, reúne todos esse sentidos, o sentido de estrangeiro, o sentido de hospitalidade, de hospitalidade ao estrangeiro, o sentido do viajante, (o nômade, tão importante para Flusser), e o sentido do inimigo. Segundo pesquisas linguísticas, a palavra hostis vem do indo-europeu ghosti, que significava, em indo-europeu, "inimigo" e "estrangeiro". Então, entra em pano de frente a figura do "inimigo", e daí vem o sentido de hostil em português. Então hostilidade procede da mesma raiz de inóspito e de hospitalidade. E por aí temos um bom número de palavras que nascem da mesma raiz tais como hospital e hospicio.

O conceito, portanto, de inóspito é um conceito originalmente espacial. Tem a ver com o espaço, pois denomina o viajante (o hóspede) e o estrangeiro. É o que habita um outro espaço, diferente do nosso e transita pelo nosso.O conceito tem ainda uma dimensão de perigo e de ameaça; pois traz em sua vestimenta de forasteiro a possibilidade de ocultar um inimigo, aquele que vai roubar, saquear e matar. Mas também o conceito de perigo possui uma raiz profunda associada ao espaço. O espaço do abrigo, a proximidade e o pertencimento ao grupo são decorrências do perigo do transitar. A própria palavra 'perigo' tem o prefixo indo-europeu 'per' que significa deslocar-se.

\footnotetext{
1 Texto elaborado a partir da fala do professor Norval Baitello Júnior no Simpósio Flusser em Fluxo, que aconteceu nos dias 24 e 25 de maio de 2012 na Universidade Federal do Ceará. Transcrição de Emerson Cunha e Érico Lima, revisado pelo autor. Currículo do autor: http://lattes.cnpq.br/7181181691875740.
} 
FLUSSER STUDIES 15

O tema do espaço, para Vilém Flusser, é um problema central. Ele pronunciou uma frase notável, depois reverberada e transformada em epígrafe por um outro pensador contemporâneo que o admirava, e, ao mesmo tempo, era criticado por ele: o sociólogo e filósofo Dietmar Kamper. "Espaço, eis aqui as minhas dores.", em alemão: "Raum, das sind meine Schmeržen."

\section{O espaço e a fantasia}

Em um dos cursos que Flusser ministrava às quartas-feiras, na sua casa, para um pequeno grupo de jovens ouvintes, sobre o grande tema Causalidade, havia uma aula dedicada ao espaço. O mini-curso contava com apenas três grandes aulas O Tempo, O Espaço e A Causalidade. Mas, como pesquisador, pensador e escritor obsessivo, mesmo os cursos que dava na sua casa, para os amigos de seus filhos, na Rua Salvador Mendonça, eram rigorosamente escritos. Tais manuscritos ou tiposcritos (pois eram sistematicamente datilografados) oferecem hoje uma importante fonte de pesquisas para as raízes do pensamento flusseriano, embora continuem, na sua grande maioria, não publicados.

Vamos então aqui à segunda aula, ao grande tema $O$ Espaço. Escreveu Flusser, iniciando sua aula: "Quando falei do tempo, na última quarta-feira, disse que a nossa fantasia não funciona no seu campo. Exatamente o oposto acontece com o espaço. O tempo nos parece abstrato. E somente quando nos aprofundamos no seu estudo, verificamos que ele é o que há de mais concreto. O espaço nos parece concreto e palpável, e é somente mais tarde que verificamos ser ele o que há de mais abstrato. A nossa fantasia funciona bem demais no campo do espaço. Ele dá uma aura de realidade palpável que desaparece na luz fria do intelecto. Aventuro-me à seguinte tentativa de explicação dessa diferença de nossa atitude: $O$ nosso corpo dispõe de um órgão, meio interno, meio externo, o labirinto, graças ao qual nos orientamos dentro do espaço. Talvez seja ele responsável pela ilusão do espaço concreto que nutrimos com tamanha persistência. De passagem seja dito que esse órgão tem três alas, as quais criam a ilusão de três dimensões do espaço. Creio, portanto, que nunca poderemos imaginar um espaço com mais dimensões, não podemos jamais ter a vivência do mundo Einsteiniano. Podemos, no entanto, isto sim, imaginar seres com labirintos de quatro ou de vinte e quatro alas. E aqueles entre vocês que tem imaginação biológica e inclinação literária talvez inventem um mundo de monstros e marcianos assim, que vivem dentro de um espaço de dimensões multiplicadas. A imaginação de Hollywood, tão ingênua e inocente e que se limita a mutações inócuas de formas terrestres, talvez ficaria enriquecida." (Flusser, V. Curso: Causalidade. Tiposcrito inédito). 


\section{FLUSSER STUDIES 15}

Desenvolvendo aqui a relação do espaço com a fantasia, o autor associa a ilusão de concretude do espaço a um fundamento biológico, mas prossegue apontando as diversidades culturais da percepção do espaço no conflito entre o conceito judaico e o conceito grego de espaço. "Somos, portanto, biologicamente limitados ao espaço de três dimensões, ao espaço humano. É a forma, a Gestalt da qual o mundo das coisas externas se apresenta. As tentativas do espírito humano de romper essa forma, de conceber um espaço diferente, (por exemplo, um espaço sem dimensão, como o brâman, ou um espaço de múltiplas dimensões, como os espaços riemannianos), dão prova de que esse espírito não é totalmente condicionado biologicamente e supera a limitação do corpo. $\mathrm{O}$ fato da capacidade de nosso espírito de superar precariamente a sua limitação biológica é, para mim, um argumento decisivo contra a aceitação das filosofias existencialistas, que insistem tão desesperadamente na vivência e se restringem, portanto, à limitação biológica, relegando o resto à metafísica, (uma palavra feia na boca dos existencialistas). Podemos, é verdade, viver e imaginar somente um espaço de três dimensões, mas podemos conceber outros espaços, e esses outros espaços podem adquirir uma realidade superior ao espaço vivido. A história do pensamento humano, e mais especialmente do pensamento ocidental, fornece exemplos dessa afirmativa. [...] Para os gregos, o espaço abrange toda a realidade, ou é totalmente irreal e esconde a realidade como um véu, a qual transparece por ele. Nas duas alternativas, o espaço está fechado sobre si mesmo, não há nada que dele participe e o transcenda simultaneamente. O espaço dos judeus, no entanto, tem este caráter aberto e dubioso. Devido ao caráter linear e histórico da noção judaica do tempo, o espaço é aparentemente finito temporalmente, ele foi criado e será liquidado. A Bíblia não se explica em termos claros nem sobre a criação nem sobre a liquidação do espaço, talvez por tratar-se de processos inconcebíveis para a mente humana. Não resta dúvida, no entanto, que Deus participa do espaço e nele influi, mas o transcende e, de certa forma, o envolve. O espaço dos judeus está como que ligado por uma corda umbilical ao mundo transcendental além do espaço. Através dessa corda umbilical corre o tráfego metafísico entre Deus e os homens. [...] Para os judeus, portanto, não surge o problema da realidade ou irrealidade do espaço. Ele é real por ser uma criação de Deus e por comunicar com ele, mas a realidade divina transcende a realidade do espaço.” (Flusser, V. Curso: Causalidade. Tiposcrito inédito )

Flusser continua em sua reflexão sobre a gênese do conceito de espaço, abordando a síntese promovida pelo Cristianismo a partir do pensamento hebraico e do grego. "O cristianismo efetuou uma síntese destes dois espaços, mas não creio que se trata de uma síntese criadora. Se analisarmos a nossa noção de espaço intuitivamente, receio que encontraremos as duas noções ainda bem 


\section{FLUSSER STUDIES 15}

separadas no fundo da nossa alma. Hoje em dia talvez não diremos que temos um espaço judaico e um espaço grego, diremos que temos uma noção física e uma noção psicológica do espaço.” (Flusser, V. Curso: Causalidade. Tiposcrito inédito).

A partir desse conceito cindido de espaço, vamos retomar aqui o nosso tema original, o inóspito como a qualidade do espaço que abriga o hostil, ou a hospitalitas, a condição do estrangeiro, que nos abriga a todos e, ao mesmo tempo, é a hostilidade do espaço. Embora pudesse começar pelo espaço aéreo das copas das árvores, habitat de origem de todos os primatas, (como o fiz em meu livro $O$ pensamento sentado), um maior rigor histórico coloca o nascimento do humano no espaço plano da savana, ou seja, no chão, com o andar ereto e bípede.

\section{O chão}

Flusser, no ano de 1990, participou de mais um (seu penúltimo) pequeno mas importantíssimo simpósio numa aldeia do sul da Alemanha, organizada pelo comunicólogo e pensador Harry Pross. Uma aldeia de mil e duzentos anos de idade e setecentos e cinquenta habitantes, e que abrigava por uma semana os maiores pensadores transversais do seu tempo para discutir questões do momento, sobretudo questões da comunicação. Os chamados "Seminários do Celeiro" tinham a cada ano um tema. Um ano foi o brinquedo, o jogo; outro ano, foi a comida depois de Tchernobil; depois a pátria, os amigos e os outros, o kitsch na mídia, e, um dos anos, foi o euronomadismo. Era a época justamente em que havia grandes correntes migratórias por conta das novas fronteiras europeias que se desenhavam. Flusser proferiu naquele ano uma palestra chamada Reflexões Nômades (posteriormente publicada em seu livro Medienkultur). É uma palestra como sempre transversal e provocadora. Diz ele que o homem passou por três grandes catástrofes; o homem foi plasmado, na verdade, por três grandes catástrofes. A primeira delas se chamava hominização. Foi com a redução do habitat florestal, das florestas tropicais que o animal que vivia nas copas das árvores foi obrigado a descer e entender-se com o chão. Como nós sabemos, o chão para os primatas, que viviam nas árvores, é o ambiente mais hostil que pode existir. $\mathrm{O}$ macaco não temia nada mais, nenhuma outra coisa era tão temida quanto cair, ir ao chão. Porque lá estavam todos os grandes predadores e todos os pequenos perigos, e as pequenas ameaças à sua integridade: insetos, répteis, além de outros predadores. E, com esta mudança climática, o macaco é obrigado a descer e é obrigado a se entender com o chão, e se transforma a partir deste espaço inóspito do chão. 


\section{FLUSSER STUDIES 15}

Esse diálogo difícil com o chão, que transforma os pés e as mãos deste primata, transforma profundamente o seu corpo, a sua postura, a sua vida, a sua maneira de se movimentar, a sua maneira de se comunicar. Foi a primeira grande catástrofe do homem, que criou o ser humano, a hominização.

Vamos buscar antes a etimologia da palavra "chão". "Chão", em português, vem do latim planum, que também dá a palavra "plano". Então, sabemos que é uma superfície, e, hoje, se diferenciou “chão" de "plano". O chão pode não ser tão plano. Mas, enfim, as duas palavras vem da mesma raiz. E, se vamos mais fundo nessa etimologia, veremos que a palavra planum, do latim, vem da palavra indo-europeia pelt, que significa, ao mesmo tempo, "chão" e "cheio" ou então "plano" e "pleno". Como em espanhol, llano e lleno. que vêm da mesma raiz. Imaginemos o que define o chão para um animal que desce das copas: o lugar cheio de coisas, cheio de outros, cheio de animais, cheio de perigos. Portanto, o chão era o espaço mais inóspito que se podia imaginar. $\mathrm{Na}$ mesma época de sua palestra nos Seminários do Celeiro, Flusser já estava escrevendo dois outros livros Vom Subjekt qum Projekt (Do Subjeto ao Projeto) e Menschwerdung (Hominização)que permaneceram inacabados. O autor fala aí da metáfora do balão em oposição ao chão, a vida como balão (no vazio) e a vida no chão (no cheio). O vazio seria a situação paradisíaca da ausência de ameaças e da ausência de perigos, e o cheio seria justamente a presença maciça e massiva de todos esses perigos. Os dois conceitos: o da gravidade e o do balão de ar são as duas concepções de espaço em choque. A gravidade seria o cheio, o contato com o chão, e o balão de ar seria a vida anterior, digamos, a vida capsular na copa das árvores ou a vida futura libertada amarras do chão, o espaço das promessas míticas. Mas a gente sempre idealiza as situações passadas. Existe aí embutida uma figura muito importante para o pensamento de Flusser, que é a figura da saudade. Uma vez que a conquista do chão não se deu sem

tropeços e perdas, desenvolveu-se uma "estratégia do tropeço" O chão (cheio) produziu como contraparte uma saudade filogenética do vazio, uma saudade de ser aquela espécie anterior que vivia nas copas das árvores, no vazio.

\section{O deserto}

O nomadismo gerou o homem. Num determinado momento, este chão que (mal) acolheu o nômade se torna ainda mais árido, ainda mais inóspito. No espaço de passagem deste nômade para a conquista do mundo havia desertos a serem atravessados. E o deserto, de novo, é uma configuração que apresenta o vazio e um cenário que se abre para as projeções, vamos dizer assim, para os 


\section{FLUSSER STUDIES 15}

projetos da imaginação. Porque, no deserto, a variante do plano, a contradição, a paisagem, o extremamente seco é inumano, é impossível para a vida, e o vento, invisível mas palpável, é onipresente. E, portanto, o homem passa a viver o vento e a sentir o vento como o deus que o impulsiona, o deus do nômade. O nômade vai para onde o leva o vento, se orienta pelos ventos, e os ventos não se oferecem aos olhos, requerem mediações para serem recebidos.

De novo, vemos que existe aí a presença do vazio, só que é um outro vazio, um vazio seco diferente daquela saudade filogenética do vazio, do aconchego úmido e uterino das sombreadas entranhas vegetais. Agora o vazio que teremos que enfrentar é seco e fustigado pelo sol. Por isso é um vazio que compele para frente, que obriga os passos rumo ao futuro, um vazio repleto de obrigatórias visões internas, calculadas, meditadas, planejadas. Se atravessarmos esse vazio, portanto, estaremos salvos. A palavra árabe para vazio é cifr, nos ensina Flusser. Dela nasceram as palavras “cifra”, “cifrão”, “cifrar”, “decifrar”. E a palavra "cifra”, “operar com cifras”, com vazios, é aquilo que chamamos de "calcular". Foi lá, neste ambiente, inóspito, que nasceu a matemática, a contabilidade, a escrita, a astronomia, nas culturas que nasceram nesse vazio do deserto. Os deuses do vento, deuses invisíveis, do vento invisível, foram aqueles que criaram, conduziram, ensinaram o homem a conduzir o seu pensamento por estradas abstratas. As escalada das não-coisas diagnosticada por Flusser é, portanto, um subproduto do ambiente desértico, seco e duro, e sua crença na abstração.

O filósofo japonês Tetsuro Watsuji, autor de Antropologia da Paisagem faz um estudo instigante do deserto como paisagem geradora de cultura. Para Watsuji, há três grandes padrões de paisagens geradoras de cultura: as paisagens monçônicas, as paisagens desérticas e as paisagens pastoris. Diz ele da paisagem do deserto que ali nasceram as grandes religiões monoteístas. E a grande contribuição das culturas do deserto foi a do deus pessoal: é o deus judaico, como também é o deus cristão, assim como o é o deus islâmico. São deuses enérgicos que só ajudam a quem se ajuda. Castigam aos que não se agregam e aos que não enfrentam as adversidades. Assim, do extremamente inóspito nasce uma cultura geradora de vigorosas formas de pensamento abstrato. Toda a nossa ciência ocidental, portanto, é desértica, nasce do deserto, opera com vazios, opera com zeros, com cifras, com imagens e abstrações. 
FLUSSER STUDIES 15

\section{A casa}

O próximo ambiente inóspito é a casa. Aqui retomamos o tema das três grandes catástrofes. A segunda grande catástrofe do homem foi aquela que aconteceu há aproximadamente dez mil anos Flusser a chama de civilização. Foi o momento em que o nômade se assentou e passou a viver em espaços fixos, cultivar plantas e a criar animais. E, portanto, estava preso à terra. E o argumento de Flusser, de novo, é um argumento etimológico portanto, arqueológico. Como estava palestrando em alemão, lançou mão das palavras alemãs sitz̧en (estar sentado) e besitz̧en (possuir), demonstrando que esta só é possível quando existe aquela. Era impossível ao nômade acumular posses, mas o assentado descobre o universo das posses e da riqueza. Flusser não traduziu seu texto para o português por fatalidade, mas se o tivesse feito, não teria encontrado dificuldade na transposição dos conceitos que se confirmam nas línguas latinas: sedere, em latim, é irmão de possedere. Sedere é "assentar", "sentar-se" ou "estar sentado", e possedere é "possuir". A partir do assentamento, o homem passa a possuir coisas e passa a viver num espaço físico delimitado e protegido. Como passa a ter bens, precisa controlar, contabilizar suas posses e transações. Dessa contabilidade inicial surge a escrita. A casa também constitui um espaço, em princípio, vazio e, portanto, amigável, que protege das intempéries, da chuva, do vento, do frio, dos predadores. Portanto, reproduz o vazio idílico das copas das árvores. Mas acontece que ela começa a se encher com posses, pessoas e possibilidades, com coisas concretas e com abstrações. Enquanto a família nômade era uma família de alta rotatividade, só os mais vigorosos suportavam, a sobrevivência nas habitações poderia ser mais longa e a casa vai ficando cheia. De novo, o fenômeno do chão se transporta para o fenômeno da casa. Mas ainda não são as pessoas que tornam as habitações inabitáveis, são as possibilidades, as não-coisas, as possíveis pessoas, as coisas possíveis e impossíveis trazidas em turbilhões por todos os orifícios da casa. O espaço se satura com os outros, os hóspedes em imagens e vozes em fluxo ininterrupto. O espaço físico e o espaço psicológico não mais dialogam um com outro.

\section{O outro, os outros}

A casa se enche de outros, de hóspedes, hóspedes que são, no seu profundo íntimo, hostis. E gera ainda um outro problema, um terceiro ou um quarto problema, que seria o problema do lixo, o problema dos restos do consumo, que exigem que a própria ciência crie uma nova categoria para 


\section{FLUSSER STUDIES 15}

lidar com os objetos do mundo, a categoria das ciências arqueológicas, as ciências que vão cuidar das camadas soterradas de nossa existência. Assim, o lixo é o grande ícone do outro, aquilo que não incorporamos em nossas vidas, que apenas passa por elas e é descartado.

E é justamente descartado porque é inóspito. E é inóspito, mas é constitutivo de nossa complexa maneira de existir, porque foi criado dentro da nossa própria casa. Também por isso ele é invasivo. E o outro invasivo se multiplica, nos tempos atuais, e se expande em vertiginosa ascensão, porque necessitamos cada vez mais desse espelhamento no outro, uma vez que a sociedade mediática gerou uma crise de alteridade. Flusser repetiu muitas vezes a frase "We shall survive in the memory of others". Tal frase constitui, sem dúvida, um diagnóstico, mas soa mesmo subterraneamente como uma ameaça. O artista húngaro Miklos Peternak usou tal frase de Flusser para nomear o DVD que reúne importantes falas e palestras do autor. Entregamos nossa sobrevivência nas mãos do outro, dos outros. Isto quer dizer também que nossas memorias caem em terreno árido.

Flusser publicou, a respeito desse tema, do outro, um pequeno artigo na revista Shalom, em agosto de 1982, ao qual deu o nome de "Ame (sic) o teu outro como a ti próprio". E aqui ele trata da temática do outro, do outro justamente como as teologias, desde o Judaísmo ate o Cristianismo, prescrevem a aproximação e o relacionamento com esse inóspito chamado outro. Formulada por Hillel esse "Ama o teu outro como a ti próprio" é transformada no Novo Testamento em "Ama o teu próximo como a ti mesmo". É muito diferente amar o próximo. Amar o outro significa amar o desconhecido, amar o inimigo. E amar o próximo significa amar um quase-eu, dentro de um território circunscrito. Diz Flusser que "este é um problema da antropofagia, tão antigo quanto a humanidade. O problema de devorar o outro, que significa devorar o deus". O inóspito outro é, na verdade, uma imago do inóspito do "eu-mesmo".

\section{O espaço inóspito do eu-mesmo, do nós-mesmos}

O último ou mais recentemente buscado espaço do inóspito é o "eu mesmo". Embora as psicologias profundas já o venham tentando desvendar há mais de um século, tal espaço complexo oferece um desafio sempre novo. Flusser adota outra direção para o eu-mesmo, talvez melhor faríamos se chamássemos esse espaço de "nós-mesmos", uma primeira pessoa sim, mas no plural, com um "nós" antropológico. A expressão mais espacial do “eu mesmo” é o corpo e seus tentáculos que constroem o chamado "Lebenswelt" (mundo vital), o degrau mais alto da escada descendente da abstração. Em 


\section{FLUSSER STUDIES 15}

muitos escritos, Flusser trata direta ou indiretamente do tema do corpo, mas sobretudo dos gestos. O gesto é a produção do corpo em movimento. Este corpo vai se transformando, vai se fabricando a si mesmo ao longo das catástrofes. Vai se transformando em um objeto estranho a si mesmo, porque passa a ser uma confluência de vetores temporais e espaciais que exigem que ele seja muito mais rápido que sua biologia. E, portanto, este corpo, a concretude máxima do "nós-mesmos" (e ao mesmo tempo sua máxima abstração) enfrenta a grande dificuldade de ser espaço-tempo, de ocupar espaço, ser existência física e presença, diante de um mundo que se encheu de vazios e ausências, os vazios-ausências ansiados pela saudade filogenética do homem. Com isso criamos um presente de difícil conquista e de difícil convívio. Dietmar Kamper, em seu livro Abstrações do corpo, um livro sobre o pensamento flusseriano, se dedica ao tema da dificuldade antropológica de se manterem as dimensões soterradas do corpo em uma era de ambientes tão inóspitos ao pensar corporal (KoerperDenken).

Há invariavelmente três elementos que fazem parte desta inospitalidade do eu mesmo, do nósmesmos. O primeiro é a saudade, a ânsia pelo vazio filogenético ancestral. O segundo é o projeto: não somos mais sujeitos nem objetos, todos nós somos projetos, portanto vivemos à frente, projetando-nos. Esta é a ânsia pelo futuro. E o terceiro elemento é a morte, a não-coisa mais palpável percebida pela consciência do homem, fundadora do próprio humano, força motriz de toda comunicação e motivação para nossa entrega de nós-mesmos ao mundo das imagens.

Cito aqui uma frase de Flusser, do livro inacabado Do Subjeto ao Projeto: "Algum núcleo duro do eu, um self, uma alma, prova-se como não-coisa lógica e existencial’. Portanto, o núcleo duro do eu é uma não-coisa.

O que caracteriza assim a terceira catástrofe, aquela que mal começou e nem sequer nome tem? Depois de apenas dez mil anos de vida sedentária, assentados em nossas casas, aldeias e cidades, a casa ficou tão inóspita que voltamos a ser nômades, sem casa, hóspedes hostis, o outro dos outros. Confrontamo-nos com o inóspito do "nós-mesmos", em um embate entre nossos próprios deuses e demônios arrancados de seu refúgio e, ao mesmo tempo, condenados a um aprisionamento no espaço devassado por todo tipo de hóspedes estranhos, fantasmas, imagens e fantasias. 


\section{FLUSSER STUDIES 15}

\section{Referências $^{2}$}

Baitello, N. (2007). Flussers Völlerei. Köln: Walther König.

Baitello, N. (2010) A serpente, a maca e o holograma. S. Paulo: Paulus.

Baitello, N. (2012) O pensamento sentado. S. Leopoldo: Ed. Unisinos.

Flusser, V. (s.d.). Causalidade (Curso) tiposcrito inédito

Flusser, V (1982). "Ame teu outro como a ti mesmo". In Shalom, agosto 1982. São Paulo. P. 68-9.

Flusser, V. (1998). Vom Subjekt zum Projekt. Menschwerdung. Frankfurt/Main: Fischer.

Flusser, V. (1998). Medienkultur. Frankfurt/Main: Fischer.

Flusser, V. (1994). Los Gestos. Barcelona: Herder

Kamper, D. (1999). Körper-Abstraktionen. Das anthropologische Viereck von Raum, Fläche, Linie und Punkt. Köln: Walther König.

Peternák M. (2010) We shall survive in the memory of others. Köln: Walther König

Watsuji, T. (2006). Antropología del paisaje. Climas, culturas y religiones. Salamanca: Sígueme.

${ }^{2}$ Estas referências foram acrescentadas posteriormente, quando o professor Norval Baitello Junior revisou o texto transcrito. 